\title{
Hot filament assisted deposition of silicon nitride thin films
}

\author{
Sadanand V. Deshpande, Jeffrey L. Dupuie, a) and Erdogan Gulari \\ Department of Chemical Engineering. University of Michigan, Ann Arbor, Michigan 48105
}

(Received 27 May 1992; accepted for publication 20 July 1992)

\begin{abstract}
Hot filament assisted chemical vapor deposition (HFCVD) of silicon nitride thin films was studied with disilane $\left(\mathrm{Si}_{2} \mathrm{H}_{6}\right)$ and ammonia $\left(\mathrm{NH}_{3}\right)$ as the source gases. High optical density films were obtained at a low substrate temperature $\left(375^{\circ} \mathrm{C}\right.$ ) and high deposition rates (up to $1700 \AA / \mathrm{min}$ ). The effects of disilane flow rate, filament temperature, and disilane carrier gas composition on film properties were investigated. Transmission infrared measurements showed low hydrogen content $(<5 \%)$ in the films. Sputter depth profiling using $x$-ray photoelcetron spectroscopy indicated high film purity with only surface oxygen contamination from air exposure after deposition.
\end{abstract}

Amorphous silicon nitride $\left(\mathrm{SiN}_{x} \mathrm{H}_{y}\right)$ films are used in integrated circuit manufacture as oxidation masks, gate dielectrics, interlevel insulators, and final passivation layers. Conventionally, $\mathrm{Si}_{3} \mathrm{~N}_{4}$ thin films are deposited at high substrate temperatures $\left(700-900^{\circ} \mathrm{C}\right)$ by thermal CVD and at low temperatures $\left(200-400^{\circ} \mathrm{C}\right)$ using plasma methods. ${ }^{1,2}$ Low-temperature deposition of silicon nitride is particularly important in compound semiconductor technology as a passivation and capping material, and in processes where thermal budgeting is critical. The major problem in conventional low-temperature depositions is the high amount of hydrogen incorporation $(10 \%-30 \%)$ in the films which leads to high etch rates (up to $2500 \AA \AA \mathrm{min}$ ) in buffered HF solutions. ${ }^{3}$ In this study we report the use of a hot filament assisted CVD technique to deposit silicon nitride thin films at high rates, low hydrogen content, and low substrate temperature with disilane and ammonia as reactants.

Ilot filament assisted CVD (HFCVD) has been successfully used in the past to grow polycrystalline diamond thin films. ${ }^{4-6}$ It has also been used to deposit amorphous silicon nitride using both monomethylamine ${ }^{7}$ and ammo$\mathrm{nia}^{8}$ as nitrogen sources and silane as the silicon source. In another study, hexagonal boron nitride was deposited using borazine as the single source precursor. ${ }^{9}$ We have previously reported ${ }^{10}$ the use of HFCVD to deposit high purity aluminum nitride thin films at low substrate temperatures. We have also used this technique to deposit silicon nitride films with silane and ammonia as reactants. ${ }^{11}$ A hot filament (usually tungsten) is a simple method of activating reactant gases to form the necessary precursor species for deposition of high quality thin films at low substrate temperatures.

The experimental system used in this study was the same as reported previously. ${ }^{11}$ Briefly, the reactor consists of a cold wall, 6 in., six way stainless-steel chamber. The reactor pressure was measured with a capacitance manometer and controlled by an exhaust throttle valve. Reactant gases were fed into the reactor via two inlets: one to feed ammonia which flowed over the filament and the other was a gas dispersal ring that bypassed the hot filament to de-

\footnotetext{
a) Present address: Contamination Engineering, Motorola Inc., Austin, TX 78721 .
}

liver disilane with the carrier gas. The substrates were clamped to a stainless-steel susceptor heated by two cartridge heaters. The substrate temperature was monitored using a type $\mathrm{C}$ thermocouple clamped to the susceptor surface close to the substrate. The filament was a resistively heated tungsten wire (diam $\sim 0.25 \mathrm{~mm}$ ) placed $4 \mathrm{~cm}$ away from the substrate. The filament temperature was measured with an optical pyrometer through a quartz viewport on the reactor. The silicon nitride films were deposited onto 2 in. $p$-type silicon (100) wafers. The substrales were cleaned with solvents and stripped of the native oxide with $10 \%$ HF just prior to deposition. The deposition parameters used in this study are summarized in Table $\mathbf{I}$.

The deposited films were characterized by ellipsometry, infrared spectroscopy, and $\mathrm{x}$-ray photoelectron spectroscopy (XPS). The film thicknesses and refractive indices were measured by an ellipsometer at $632.8 \mathrm{~nm}$ and averaged over at least ten measurements. The target thickness of these filns was 2600-2900 $\AA$ ( 2 nd blue-green color under fluorescent light) in order to obtain an accurate determination of refractive index by ellipsometry. Transmission Fourier-transform infrared spectroscopy was used to determine the bonding configurations and estimate the hydrogen content in the films using the method of Lanford and Rand. ${ }^{12}$ The film composition was determined by XPS as a function of depth by $3 \mathrm{keV}$ argon ion sputter profiling.

In this study the effects of disilane flow rate, filament lemperature, and disilane carrier gas composition on film properties were investigated. In the first set of experiments the disilane flow rate was varied from 1.1 to $3.2 \mathrm{sccm}$. As shown in Fig. 1(a), the film deposition rate increased with an increase in disilane flow rate. The film refractive index also increased from 1.86 (film 1) to 2.42 (film 4). This was due to a depletion of nitrogen-containing species in the vicinity of the substrate with a higher disilane flow. A high deposition rate of $\sim 1700 \AA / \mathrm{min}$ was obtained for a disilane flow rate of $3.2 \mathrm{sccm}$. XPS sputter depth profiling of film 4 indicated that this film was silicon rich with a bulk $\mathrm{Si} / \mathrm{N}$ ratio of 1.8 . The sensitivity factors provided by the XPS spectrometer software were used for elemental analysis without further calibration. There was no detectable amount of oxygen in the film bulk. The composition of film 2 was closer to stoichiometric $\mathrm{Si}_{3} \mathrm{~N}_{4}$, with a bulk Si/N ratio of 0.95. Figure 1 (b) shows the transmission FTIR spectra 
TABLE I. Deposition parameters for $\mathrm{SiN}_{x} \mathrm{H}_{y}$ thin films.

\begin{tabular}{lc}
\hline Parameter & Set point(s) \\
\hline Reactor pressure & 0.5 Torr \\
Substrate temperature & $375^{\circ} \mathrm{C}$ \\
Filament temperature & $1500-1850^{\circ} \mathrm{C}$ \\
Ammonia flow rate & $80 \mathrm{sccm}$ \\
Carrier gas flow rate: & \\
Hydrogen & $0-230 \mathrm{sccm}$ \\
Argon & $0-142 \mathrm{sccm}$ \\
Disilane flow rate & $1.1-3.2 \mathrm{sccm}$ \\
\hline \hline
\end{tabular}

of these films. The band assignments for amorphous silicon nitride thin films have been obtained from work by Narikawa et al. ${ }^{13}$ It may be noted that as the refractive index increases, i.e., silicon content in the films increases, absorption in the $\mathrm{N}-\mathrm{H}$ stretching mode $\left(\sim 3350 \mathrm{~cm}^{-1}\right)$ decreases and the $\mathrm{Si}-\mathrm{H}$ stretching mode $\left(\sim 2150 \mathrm{~cm}^{-1}\right)$ increases. Also the shoulder in $\mathrm{Si}-\mathrm{N}$ asymmetric stretching peak $\left(\sim 840 \mathrm{~cm}^{-1}\right)$ obtained due to $\mathrm{N}-\mathrm{H}$ bending $(\sim 1175$ $\mathrm{cm}^{-1}$ ) decreases from film 1 to film 4 . This indicates that as the films become silicon rich, the population of hydrogen terminated dangling bonds shifts from nitrogen to sil-

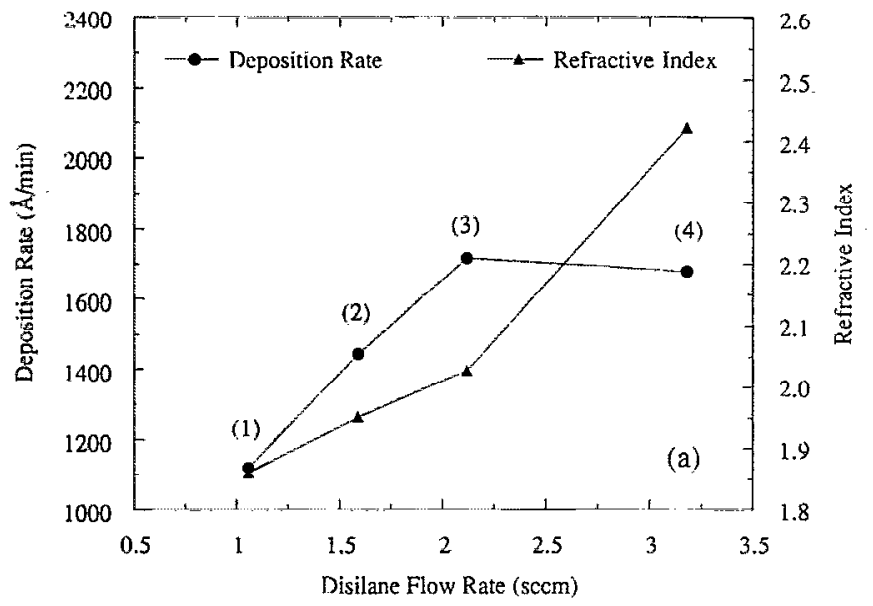

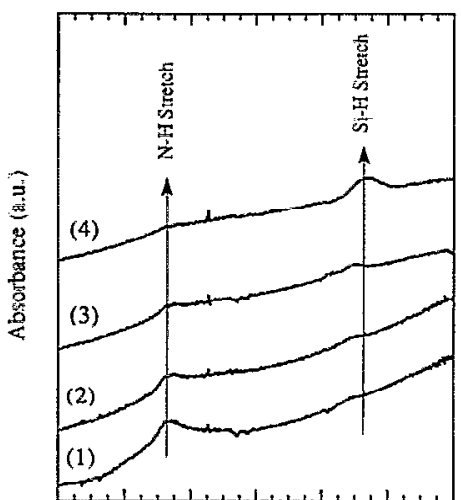

$\begin{array}{lllllll}4000 & 3600 \quad 3200 & 2800 & 2400 & 2000 & 1600\end{array}$

Wavenumber $\left(\mathrm{cm}^{\cdot \mathrm{t}}\right)$

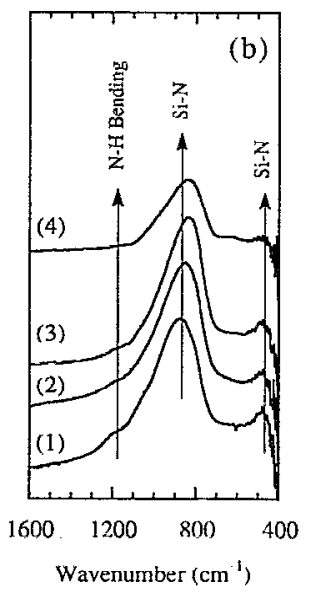

FIG. 1. (a) Effect of disilane flow rate: filament temperature $=1700^{\circ} \mathrm{C}$, $\mathrm{H}_{2}$ carrier flow rate $=230 \mathrm{sccm}$, ammonia flow rate $=80 \mathrm{sccm}$, and substrate temperature $=375^{\circ} \mathrm{C}$. (b) Transmission FTIR spectra of films $1-4$ shown in Fig. 1(a). The $\mathrm{N}-\mathrm{H}$ and $\mathrm{Si}-\mathrm{H}$ stretching modes have been expanded for clarity.

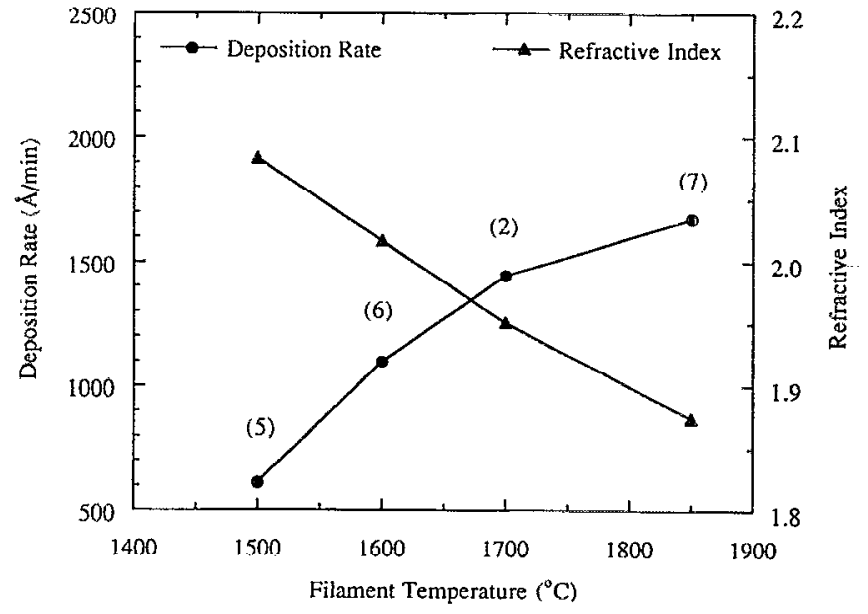

FIG. 2. Effect of filament temperature: disilane flow rate $=1.6 \mathrm{sccm}, \mathrm{H}_{2}$ carrier flow rate $=230 \mathrm{sccm}$, ammonia flow rate $=80 \mathrm{sccm}$, and substrate temperature $=375^{\circ} \mathrm{C}$.

icon. The Si-N symmetric stretching mode is observed at $490 \mathrm{~cm}^{-1}$. The total bonded hydrogen content in these films was determined to be low and was less than $6 \times 10^{21}$ atoms $/ \mathrm{cm}^{2}$. This is a definite improvement over conventional low-temperature deposition methods such as plasma CVD. ${ }^{2}$

In the second set of experiments, filament temperature was varied between 1500 and $1850^{\circ} \mathrm{C}$ for a disilane flow rate of $1.6 \mathrm{sccm}$ and hydrogen flow rate of $230 \mathrm{sccm}$. The results of these experiments are shown in Fig. 2. An increase in filament temperature would produce more of the nitrogen-precursor species, possibly $\mathrm{NH}$ radicals, in the reactor ambient and would therefore increase the film deposition rate, as was seen in these experiments. On the other hand, the film refractive index decreased due to a combination of two effects: increased amount of activated nitrogen species and a limited supply of disilane. Figure 3 shows the results of XPS sputter depth profile for film 6. This film exhibited high purity and very low oxygen content in the

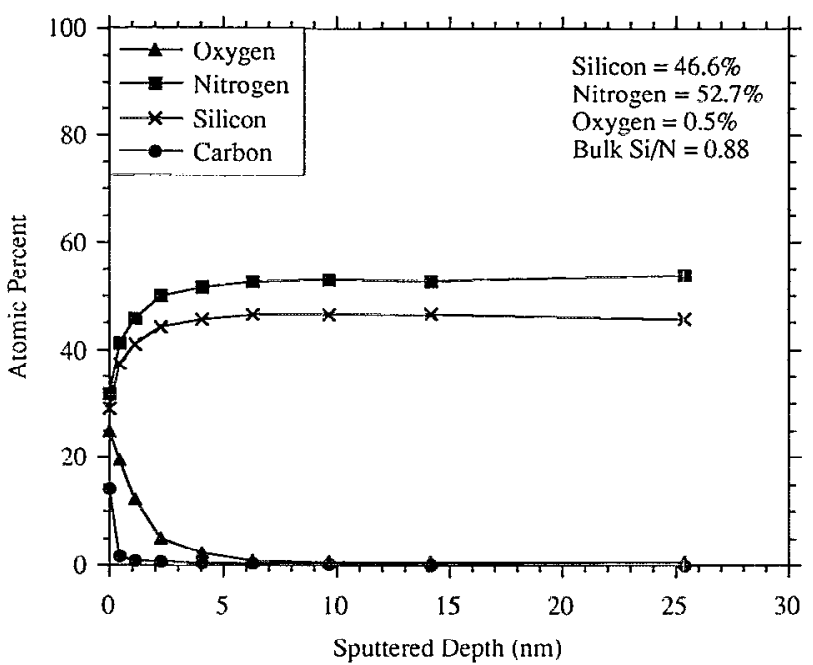

FIG. 3. XPS sputter depth profile of film 6: refractive index -2.0 , filament temperature $=1600^{\circ} \mathrm{C}$, disilane flow rate $=1.6 \mathrm{sccm}$. 


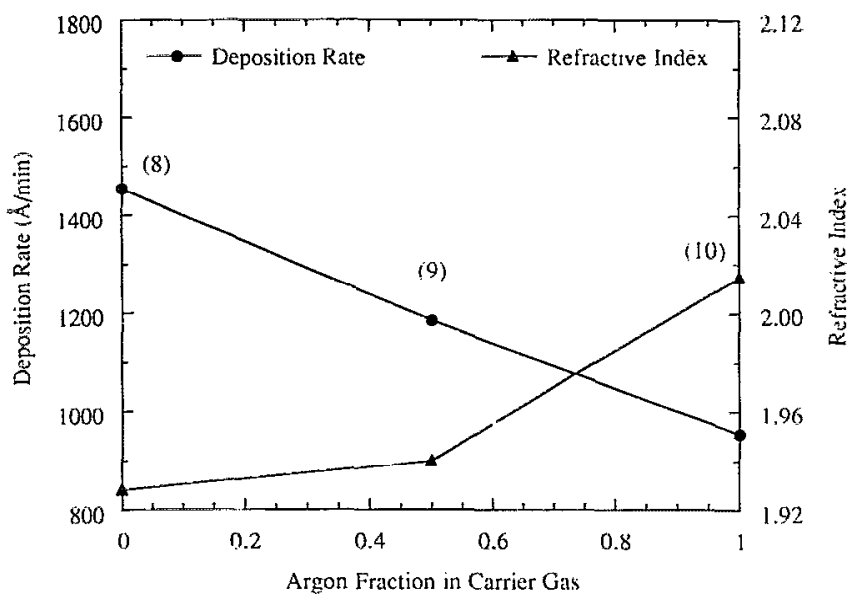

FIG. 4. Effect of argon dilution of hydrogen carrier gas: total carrier gas flow rate $=142 \mathrm{sccm}$, filament temperature $=1700^{\circ} \mathrm{C}$, and disilane flow rate $=1.1 \mathrm{sccm}$

film bulk. Oxygen is detected only in the top $15.0 \mathrm{~nm}$ of the film which indicates that this oxygen came from air exposure following deposition and not from the residual oxygen that may have been present in the reactor during deposition. XPS profiles for other films show similar results indicating that the films deposited by our HFCVD method are of high density and have low permeability for oxygen.

Finally, the composition of disilane carrier gas was varied to study its effect on film deposition rates. The total carrier gas flow rate was $142 \mathrm{sccm}$, disilane flow rate was $1.1 \mathrm{sccm}$ and the filament temperature was held at $1700^{\circ} \mathrm{C}$. As shown in Fig. 4, the film deposition rate decreases with successive increase in argon fraction of the carrier gas. Also the refractive index of films 8-10 increased indicating a decrease in nitrogen-containing species with increased argon dilution of carrier gas. The decomposition of ammonia on a hot platinum filament $\left(>1000^{\circ} \mathrm{C}\right)$ has been studied with laser-induced fluorescence by Selwyn and $\mathrm{Lin}^{14}$ under pressure conditions similar to those used in this study. Their results indicated that the rate of $\mathrm{NH}$ radical production by catalytic action of the filament increased with increasing filament temperature, and also with addi- tion of hydrogen to the gas mixture. The addition of hydrogen is believed to enhance the desorption rate of $\mathrm{NH}$ radicals from the filament surface. In this study, argon dilution of the hydrogen carrier gas may have caused a decrease in NH radical desorption rate leading to a decreased film deposition rate.

In conclusion, we have demonstrated that the hot filament assisted chemical vapor deposition method can be extended to the deposition of high purity and high density silicon nitride thin films from disilane at high deposition rates. The deposition rates obtained here were higher than the rates of $1000 \AA / \mathrm{min}$ previously reported by another group using similar deposition method. ${ }^{8}$ The films exhibited low levels of hydrogen incorporation at a low substrate temperature of $375^{\circ} \mathrm{C}$. This simple method affords great versatility in deposition of high quality thin films with varied properties. It can easily be extended to other nitride thin films.

We wish to thank Steve Brown of the Applied Physics Department at the University of Michigan for use of the optical pyrometer. We would also like to acknowledge the National Science Foundation for partial support for this project.

${ }^{1}$ K. E. Bean, P. S. Gleim, and R. L. Yeakley, J. Electrochem. Soc. 114, 733 (1967).

${ }^{2}$ A. J. Lowe, M. J. Powell, and S. R. Elliot, J. Appl. Phys. 59, 1251 (1986).

${ }^{3}$ A. Piccirillo and A. L. Gobbi, J. Electrochem. Soc. 137, 3910 (1990).

${ }^{4}$ B. V. Spitsyn, L. L. Builov, and B. V. Deryagin, J. Cryst. Growth 52, 219 (1981).

${ }^{5}$ S. Matsumoto, Y. Sato, M. Kamo, and N. Setaka, Jpn. J. Appl. Phys. 21, L183 (1982).

${ }^{6}$ D. G. Goodwin and G. G. Gavillet, J. Appl. Phys. 68, 8329 (1991).

${ }^{7}$ K. Yasui, H. Katoh, K. Komaki, and S. Kaneda, Appl. Phys. Lett. 56, 898 (1990).

${ }^{8}$ H. Matsumura, Jpn. J. Appl. Phys. 28, 2157 (1986).

${ }^{9}$ R. R. Rye, J. Vac. Sci. Technol. A 9, 1099 (1991).

${ }^{10}$ J. L. Dupuie and E. Gulari, Appl. Phys. Lett. 59, 549 (1991).

${ }^{11}$ J. L. Dupuie, E. Gulari, and F. Terry, J. Electrochem. Soc. 139, 1151 (1992).

${ }^{12}$ W. A. Lanford and M. J. Rand, J. Appl. Phys. 49, 2473 (1978).

${ }^{13}$ S. Narikawa, Y. Kojima, and S. Ehara, Jpn. J. Appl. Phys. 24, L861 (1985).

${ }^{14}$ G. S. Selwyn and M. C. Lin, Chem. Phys. 67, 213 (1982). 